\title{
Taxonomically Significant Colour Changes in Brevibacterium linens Probably Associated with a Carotenoid-like Pigment
}

\author{
By DOROTHY JONES AND J. WATKINS \\ M.R.C. Microbial Systematics Unit, The University, Leicester \\ AND SANDRA K. ERICKSON \\ Biochemistry Department, The University, Leicester
}

(Received 19 February 1973)

SUMMARY

\begin{abstract}
Ninety-three coryneform bacteria were tested with various acids and bases and on the basis of these tests, five of the strains were identified as Brevibacterium linens. This identification correlated with that made by other methods, thus confirming the suggestion of Grecz \& Dack (I961) that B. linens could be identified by certain colour reactions. Further studies indicated that these reactions are probably associated with the presence of a specific carotenoid-like substance located in the bacterial membrane.
\end{abstract}

\section{INTRODUCTION}

Grecz \& Dack (196I) reported that Brevibacterium linens (78 strains) gave characteristic colour reactions when the yellow-orange surface growth was treated with various acids and bases. A characteristic red colour was produced with strong bases and various shades of green and blue with strong acids. No colour changes were produced with weak bases nor with weak acids, such as lactic or formic. Under certain conditions specific colour reactions were produced with acetic acid and aniline. Yellow pigmented strains of Micrococcus, Mycobacterium, Sarcina and Staphylococcus did not give the same reactions. Grecz \& Dack suggested that the colour reactions produced with strong bases and acetic acid could be used for the rapid presumptive identification of Brevibacterium linens. However, they did not include in their survey any yellow coryneform bacteria which are frequently confused with $B$. linens, nor did they attempt to define the chemical basis of the reaction.

In view of the potential value of these tests for the identification of Brevibacterium linens, the reactions of a number of yellow, orange, pink and non-pigmented coryneform and related bacteria were investigated using the various acids and bases. An attempt was made also to characterize the pigment constituent responsible for the colour changes.

\section{METHODS}

Strains

The bacteria used were:* Brevibacterium linens ATCC9I74; NCIB $8546 ;$ B. stationis ATCC I 4403; B. leucinophagum ATCC I3809; B. imperiale ATCC $8365 ; B$. acetylicum ATCC 953.

Arthrobacter pascens NCIB 8910;A. oxydans NCIB 9333; A. aurescens NCIB 89I $; A$. ureafasciens NCIB 78II, Morris 8916 (from Professor J. G. Morris); A. citreus NCIB 8915, Morris

* ATCC, American Type Culture Collection; NCIB, National Collection of Industrial Bacteria; NCTC, National Collection of Type Cultures; NCPPB, National Collection of Plant Pathogenic Bacteria. 
8908 (from Professor J. G. Morris); A. terregens NCIB 8909; A. flavescens NCIB922I; $A$. nicotianae NCIB 9458; A. simplex Morris 89I3 (from Professor J. G. Morris); Arthrobacter spp. G93, GI09, GI54, GI62, J39, J52 (from Dr R. M. Keddie), Morris TGi (from Professor J. G. Morris), 25I, 365, 367, 368 (from Dr E. G. Mulder).

Cellulomonas uda ATCC 49I; C. cellasea $\mathrm{NCIB} 8078$; C. fimi $\mathrm{NCIB} 8980 ;$ C. gelida $\mathrm{NCIB} 8076$; C. flavigena $\mathrm{NCIB} 8073 ;$ C. bibula NCIB 8I 42;C. subalbus NCIB 8075.

Corynebacterium vesiculare ATCC I I 426; C. fascians ATCC I 2974, ATCC I 2975, NCPPB I 488; C. ilicis ATCC I 4264;C. michiganense NCPPB I468;C. betae NCPPB 363;C. flaccumfaciens NCPPB $559 ; C$. rathayi $\mathrm{NCPPB} 797 ; C$. poinsettiae $\mathrm{NCPPB} 844 ; C$. renale $\mathrm{NCTC} 7448 ; C$. equi NCTCI62I;C. aquaticum NCIB9460;C. manihot NCIB9097;C. mediolanum NClB 7206; $C$. rubrum NCIB 9433; C. diphtheriae NCTC 3989; Corynebacterium spp. NCTC75IO, EB/F64/100 (from Dr E. M. Barnes), 6-IO, 7-I I, 8-7, I I-IO from Dr H. E. Schefferle), 3A-4302, 3A-4794 (from Miss C. Shaw), c206 (M.R.C. Collection, Leicester); 'Coryneform' NCIB 8I8I, C3I I (M.R.C. Collection, Leicester).

Kurthia zopfii NCIB 8603, K2, s8, s9 (from Dr R. M. Keddie), Gardner 8 (from Dr G. A. Gardner).

Microbacterium flavum NCIB8707; $M$. lacticum NCIB8540, 854I; $M$. thermosphactum ATCC I I 509.

Mycobacterium phlei NCTC 8I5I; $M$. smegmatis NCTC 8I 59; $M$. fortuitum ATCC684I; $M$. rhodocrous NCTC8I39, NCTC 10210, 21, 417, I240, 3408, 7698 (from Dr R. E. Gordon).

Nocardia vaccinii ATCC I1092; N. cellulans NCIB 8868; N. hydrocarboxydans NCIB 9436; N. petroleophila NCiB 9438; N. saturnea NCIB 9437; N. brasiliensis 744 (from Dr R. E. Gordon); Nocardia sp. 245 (from Dr M. Goodfellow); N. turbata CI92, CI93, CI94 (M.R.C. Collection, Leicester).

Propionibacterium shermanii NCIB 8099.

\section{Media}

The bacteria were maintained on Nutrient Agar (Oxoid), and subcultured at 7 to I4 day intervals. The same medium was used for the culture of the bacteria to be tested except for Arthrobacter terregens which was grown on a soil extract medium.

\section{Reagents}

Aniline, acetic acid, potassium hydroxide, syrupy phosphoric acid (Analar grade, British Drug Houses Ltd, London); sodium hydroxide, sulphuric acid (Analar grade, Fisons Ltd, Loughborough, Leicestershire); lithium hydroxide (Laboratory Reagent grade, Fisons Ltd).

\section{Colour reactions}

A small sample of bacterial growth from the surface of an agar plate (incubated at $30^{\circ} \mathrm{C}$ for periods up to 2 I days) was transferred with a wire loop to a white tile to test for colour changes with sodium hydroxide $(5 \mathrm{~N})$, potassium hydroxide $(5 \mathrm{~N})$, lithium hydroxide (saturated solution), syrupy phosphoric acid and concentrated sulphuric acid. One or two drops of reagent were placed directly on the growth sample and colour changes noted at intervals up to $30 \mathrm{~min}$; any reaction was usually detectable in less than $5 \mathrm{~min}$. In testing with glacial acetic acid and aniline the bacterial growth was rubbed with a glass rod on to a piece of filter paper flooded with the reagent. Firm, smooth filter paper, e.g. Whatman no. I, which does not tear easily during rubbing, was used. 


\section{Extraction of pigment}

The following bacteria were used: Brevibacterium linens NCIB8546, ATCC9I74; Arthrobacter citreus NCIB 89I5; Arthrobacter sp. 25I; Corynebacterium fascians ATCC I2974, ATCC I 2975, NCPPB I 488; Corynebacterium spp. NCTC 75IO, NCIB 8I8I, 8-7, II-IO, 3A-4302; Mycobacterium phlei NCTC 8I 5I ; M. smegmatis NCTC8I 59; Nocardia hydrocarboxydans NCIB 9436; N. petroleophila NCIB $9438 ; N$. turbata Cı 92.

The bacteria were grown in $500 \mathrm{ml}$ Nutrient Broth no. I (Oxoid) in 21 conical flasks in an incubator shaker at $30^{\circ} \mathrm{C}$ for $48 \mathrm{~h}$ (Nocardia hydrocarboxydans and $N$. petroleophila for 7 days). Bacteria were harvested by centrifuging at $6000 \mathrm{~g}$ for $20 \mathrm{~min}$. The pellet was resuspended in $10 \mathrm{ml}$ of boiling methanol $\left(65^{\circ} \mathrm{C}\right)$, agitated by shaking and allowed to stand for $30 \mathrm{~min}$. The debris was removed by centrifugation at $2000 \mathrm{~g}$ for Io $\mathrm{min}$. The supernatant was examined spectrophotometrically and by thin-layer chromatography.

\section{Thin-layer chromatography.}

Hot methanol extracts ( $10 \mathrm{ml}$ ) prepared as described above were evaporated to $1 \mathrm{ml}$ by heating in a dish over boiling water, and then spotted on Kieselgel $G$ nach Stahl (E. Merck A.G. Darmstadt, Germany) plates which had been activated for $\mathbf{I} \mathbf{h}$ at $80{ }^{\circ} \mathrm{C}$. Plates were developed in one of three solvent systems: $30 \%(\mathrm{v} / \mathrm{v})$ ethanol/petroleum ether; $50 \%(\mathrm{v} / \mathrm{v})$ ethanol/petroleum ether; $80 \%(\mathrm{v} / \mathrm{v})$ ethanol/petroleum ether. $R_{F}$ values were determined visually.

\section{Spectral analysis}

Methanol extracts prepared as described were examined without further treatment in a Shimadzu 'MPS-5oL' spectrophotometer.

\section{Distribution of pigment}

Brevibacterium linens NCIB 8546 was grown in Nutrient Broth no. I (Oxoid). Approximately $6 \mathrm{~g}$ wet wt bacteria were suspended in $\mathrm{Io} \mathrm{ml} 0.005 \mathrm{M}-\mathrm{Na} \mathrm{K}$ phosphate buffer, $\mathrm{pH} 7 \cdot 2$, and sonicated for $5 \mathrm{~min}$ in I min periods with intervals for cooling. The sonicated material was centrifuged at $26000 \mathrm{~g}$ for I 5 min to obtain a bacterial extract. The supernatant from the first centrifugation was recentrifuged at $\mathrm{I} 57000 \mathrm{~g}$ for $\mathrm{I} h$ to obtain a membrane fraction. Absorption spectra were obtained for the pellet and supernatant from the second centrifugation in a Shimadzu 'MPS-50L' spectrophotometer. Relative concentrations of pigment in each fraction were determined as the $\Delta E_{450 \mathrm{um}} / \mathrm{mg}$ protein and $\Delta E_{480 \mathrm{~nm}} / \mathrm{mg}$ protein. Protein was determined by a modification of the biuret method (Gornall, Bardawill \& David, 1949).

\section{RESULTS}

Colour reactions

Sodium hydroxide, potassium hydroxide, lithium hydroxide. Only I 6 bacteria out of the 93 tested gave any colour change with $\mathrm{NaOH}, \mathrm{KOH}, \mathrm{LiOH}$. All 16 gave a red colour but the pink-red colour produced by the two strains of Brevibacterium linens and three other cultures received as Arthrobacter sp. (I) and Corynebacterium spp. (2) was easily distinguished from the orange-red colour produced by the I I strains received as Corynebacterium fascians (3), Corynebacterium spp. (3), Mycobacterium phlei (I), M. smegmatis (I), Nocardia hydrocarboxydans (I), N. saturnea (I), N. petroleophila (I). The orange-red colour did not appear to be specific for any particular taxonomic grouping. All the 16 bacteria which gave a red 
Table I. Colour reactions and spectrophotometric analyses of some yellow pigmented and related bacteria

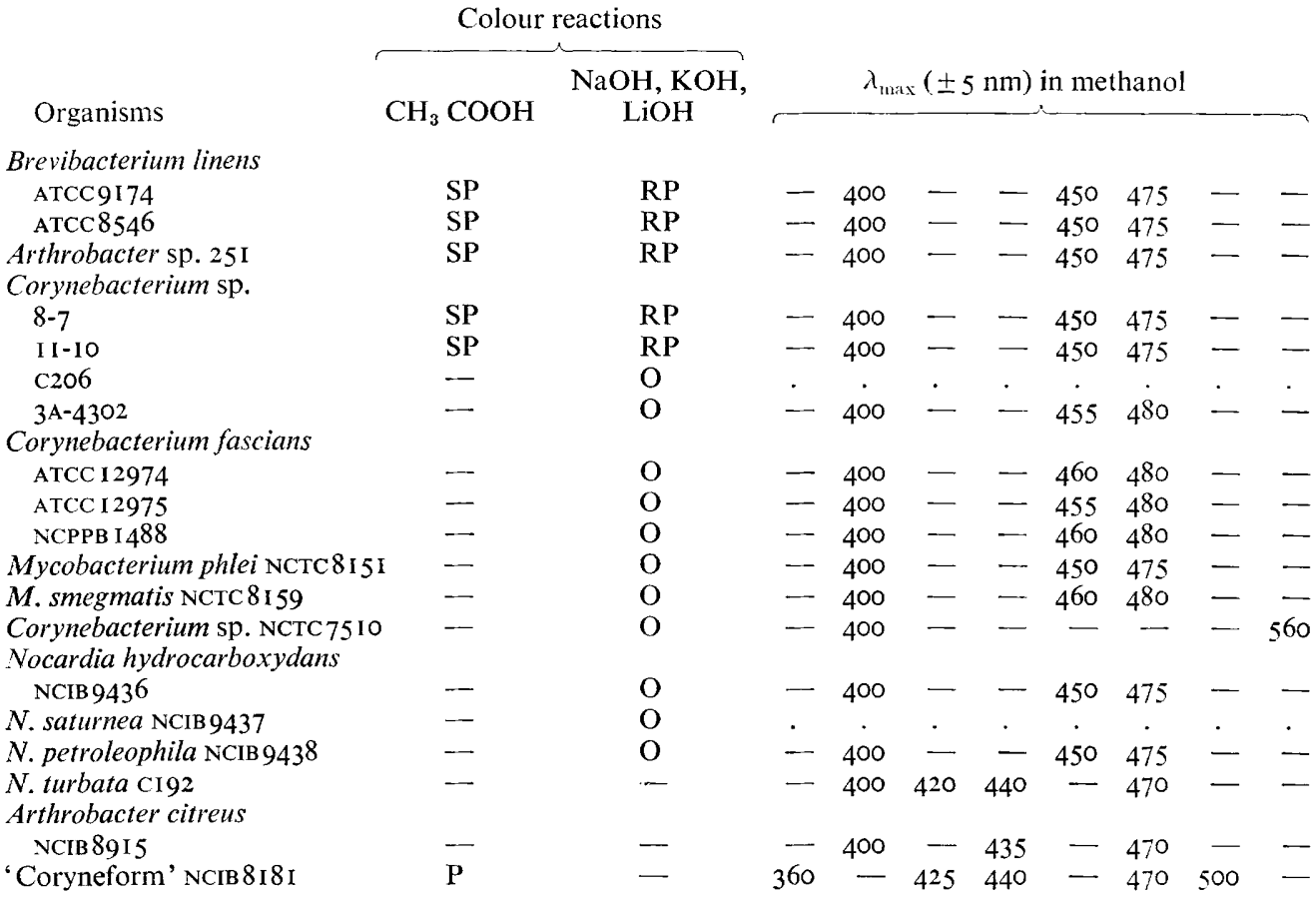

$\mathrm{P}$, purple; SP, salmon pink; RP, red pink; O, orange; - , no change; ., not done

colour produced orange or yellow pigment but in some cases the pigment was not fully apparent until the cultures were $\mathrm{I} 4$ days old. However, in every case, the colour was produced by 2 - to 5 -day cultures. The results are given in Table $\mathrm{I}$.

Sulphuric acid. The 93 bacteria tested gave a series of blue, green and brown colour reactions with sulphuric acid. The colours produced were not characteristic of any genus or species of bacteria, neither were they associated with the production of a pigment of any particular colour nor with the age of the culture.

Syrupy phosphoric acid. The results of testing with this reagent were not easy to interpret. Many of the 93 bacteria tested gave green reactions with syrupy phosphoric acid but in most cases the green colour became brown after 20 to $30 \mathrm{~min}$. No blue colour such as that reported by Grecz \& Dack (I96I) was noted with any cultures even though the tests were allowed to stand overnight.

Acetic acid. Only five of the strains tested gave a positive salmon pink reaction when growth was rubbed onto filter paper flooded with glacial acetic acid. These were the same bacteria which gave the characteristic pink-red colour with strong bases. No significant colour change was noted with any of the other bacteria with the exception of the coryneform organism NCIB 818I which produced a purple colour (see Table I).

Aniline. In our hands the reaction of the bacterial growth to aniline was not as clear-cut as that recorded by Grecz \& Dack (196I). The brick-red colour noted by them was never seen. A very faint pink colour was shown by three strains only, these were Brevibacterium linens NCIB 8546, Arthrobacter sp. 25I and Corynebacterium sp. I I-IO. 
Table 2. A comparison of thin-layer chromatography of methanol extracts of Brevibacterium linens and other bacteria

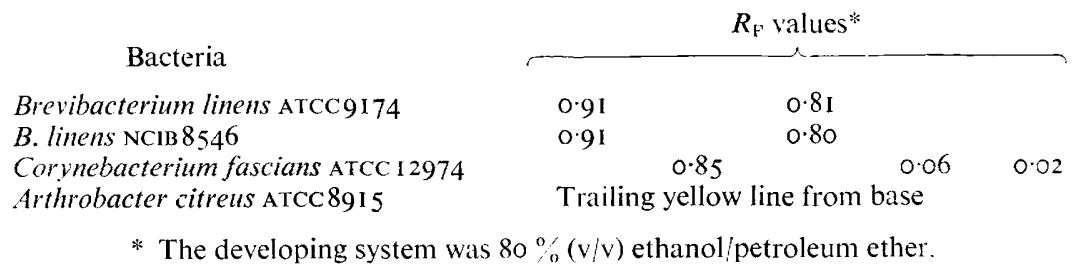

\section{Pigment studies}

Spectrophotometric analyses. Spectrophotometric analyses of methanol extracts of it of the 16 strains which gave pink-red or orange-red reactions with strong bases are listed in Table I. In addition the coryneform culture NCIB 8I8I and two organisms (Arthrobacter citreus NCIB 8915 and Nocardia turbata $\mathrm{C}$ 192) which gave no significant colour changes with any of the reagents were included for comparison. Lowering the $\mathrm{pH}$ of the methanol extracts to approx. 4 had no effect on the $\lambda_{\max }$. Raising the $\mathrm{pH}$ to approx. 9 resulted in no shifting of $\lambda_{\max }$ but did result in an intensification of the absorption in the 500 to $550 \mathrm{~nm}$ region which correlates with the red colour produced with strong bases.

Thin-laver chromatography. Four strains were examined: two gave the typical pink-red colour reactions with strong bases and the salmon pink colour with acetic acid (Brevibacterium linens ATCC9174 and B. linens $\mathrm{NCIB} 8546$ ), one gave the orange-red colour reaction (Corynebacterium fascians ATCC I 2974) and one gave no colour reaction (Arthrobacter citreus $\mathrm{NCIB} 89$ I5). Although the relative positions of the spots varied with the developing system used (see Methods) the position of the two B. linens spots was always quite characteristic. Typical $R_{F}$ values are given in Table 2 . All the spots, with the exception of two of the spots given by $C$. fascians (ATCC I2974) were yellow. Corynebacterium fascians spot approx. $R_{F}$ value 0.06 was blue and spot approx. $R_{F}$ value 0.02 was red. These two spots were very near the base line but could be measured because of their characteristic colours. When all the spots on the plates were tested with $\mathrm{KOH}$ and $\mathrm{NaOH}$ only one spot given by each of the two strains of $B$. linens $\left(R_{F}\right.$ values $0.8 \mathrm{I}$ and 0.80$)$ gave the characteristic pink colour.

Spectral investigation of the material eluted from these spots gave one peak at a $\lambda_{\text {mix }}$ value of $455 \mathrm{~nm}$ with a slight shoulder at $475 \mathrm{~nm}$.

Distribution of pigment. Investigation of the distribution of the carotenoid pigment of Brevibacterium linens $\mathrm{NCIB} 8546$ as described under Methods indicated that the carotenoid was in the membrane fraction. ( $\Delta E_{450 \mathrm{~m}} / \mathrm{mg}$ protein was 0.075 for membrane fraction and 0.026 for the supernatant fraction; $\Delta E_{400 \mathrm{~m}} / \mathrm{mg}$ protein was 0.062 for the membrane fraction and 0.019 for the supernatant fraction.) The wall fraction was unpigmented. These results agree with previous investigations of carotenoid location in bacteria (see for example, Mathews \& Sistrom. 1959).

\section{DISCUSSION}

Of 93 coryneform strains tested only five gave the characteristic colour reactions reported by Grecz \& Dack (I96r) to be typical of Brevibacterium linen.s. Two were culture collection strains of B. linens (ATCC9I74 and $\mathrm{NCIB} 8546$ ), but the other three were received as Corlnebacterium spp. (8-7 and 8-II) and Arthrobacter sp. 25I. Morphologically the three latter strains resembled other bacteria (especially Corynebacterium and Arthrobacter species) 
amongst the 93 bacteria tested. Concurrently a numerical taxonomic survey was being conducted on 233 coryneform and related bacteria including the 93 strains used here (D. Jones and $\mathbf{J}$. Watkins, unpublished). The results of the taxonomic work showed a close relationship ( $85 \%$ similarity) between the five bacteria which gave the characteristic colour reactions. This close correlation between the colour reaction of the strains and the numerical taxonomic grouping reinforces the suggestion made by Grecz \& Dack (196I) that the colour tests devised by them provide a simple and quick method for the identification of $B$. linens.

Spectroscopy (u.v. and visible) of hot methanol extracts indicated the presence of carotenoids in all bacteria tested (Table I). Only those bacteria which gave a colour reaction with strong bases showed $\lambda_{\max }$ at about $450 \mathrm{~nm}$ and there were no obvious differences between the spectra of the bacteria (Brevibacterium linens group) giving a pink-red colour reaction and those giving an orange-red reaction, with the exception of NCTC 75IO. However, thin-layer chromatographs of methanol extracts from representative bacteria (Table 2) showed a marked difference in relative $R_{F}$ values between the two $B$. linens cultures (pinkred with strong bases) and Corynebacterium fascians (orange-red with strong bases). The carotenoids of $C$. fascians have been studied in detail (Prebble, I968) but not the carotenoids of $B$. linens. We suggest that strains of $B$. linens contain a characteristic carotenoid in the cell membrane which after determination of its structure could be useful in the chemotaxonomic classification of this economically important group. However, until its chemical structure has been elucidated, the characteristic colour changes apparently due to this carotenoid found by treating intact bacteria with strong bases $(\mathrm{KOH}, \mathrm{NaOH}, \mathrm{LiOH})$ and acetic acid provide a reliable and fast identifying test for members of the $B$. linens group even when colonies have not fully developed the orange-yellow pigment. This sort of test is especially valuable in detecting coryneforms which include so many morphologically similar yellow pigmented bacteria whose status can only be determined after making many tedious tests.

We are indebted to Professor P. H. A. Sneath for his advice and interest.

\section{REFERENCES}

Gornall, A. G., Bardawill, C. J. \& David, M. M. (1949). Determination of serum proteins by means of the biuret reactions. Journal of Biological Chemistry $\mathbf{1 7 7}, 75 \mathrm{I}-766$.

Grecz, N. \& DACK, G. M. (I961). Taxonomically significant colour reactions of Brevibacterium linens. Journal of Bacteriology 82, 24I-246.

Mathews, M. M. \& Sistrom, W. R. (1959). Intracellular location of carotenoid pigments and some respiratory enzymes in Sarcina lutea. Journal of Bacteriology $\mathbf{7 8 , 7 7 8 - 7 8 7 .}$

Prebble, J. (1968). The carotenoids of Corynebacterium fascians strain 27. Journal of General Microbiology $52,15-24$. 